\title{
Attitudes of second language students towards self-editing their own written texts
}

\author{
DANIEL KASULE University of Botswana \\ VIOLET B. LUNGA University of Botswana
}

\begin{abstract}
Recognizing students' deliberate efforts to minimize errors in their written texts is valuable in seeing them as responsible active agents in text creation. This paper reports on a brief survey of the attitudes towards self-editing of seventy university students using a questionnaire and class discussion. The context of the study is characterized by its emphasis on evaluating the finished written product. Findings show that students appreciate the role of self-editing in minimizing errors in their texts and that it helps in eventually producing well-written texts. Conceptualizing writing as discourse and therefore as social practice leads to an understanding of writers as socially-situated actors; repositions the student writer as an active agent in text creation; and is central to student-centred pedagogy. We recommend the recognition of self-editing as a vital element in the writing process and that additional error detection mechanisms namely peers, the lecturer, and the computer, increase student autonomy.
\end{abstract}

\section{Introduction}

One way of recognizing students' deliberate efforts to minimize errors in their academic writing is to understand their attitudes towards self-editing. While we agree that "no learner intentionally writes strings of incoherent text" (Yates and Kenkel 2002: 43), we suspected that an attitudinal problem existed amongst our students, because of the apparent indifference exhibited in the written texts that they submitted on a writing support course we teach. This rendered their texts very tedious to read. Recurrent errors in our students' work convinced us that students do not self-edit their texts, do not appreciate its value, and deliberately wait for the lecturer to correct their errors for them. In practical terms "self-editing" is the writer's ability to independently or otherwise identify and act on textual inaccuracies and loss of clarity in content, organization and mechanics. Charles (cited in Cresswell, 2000: 235) proposed a "self-monitoring" technique where "students write marginal annotations 
about problems in their evolving compositions, to which the teacher responds". While we did not dismiss the potential of self-monitoring for improving students' final drafts, we questioned the second language (L2) writer's ability to act on errors identified via self-editing and thought that research was required, so that we could better understand the extent to which student writers take responsibility for textual accuracy, and are able to do so.

A system of assessment that focuses only on the final written product, as is the case at our university, provides unclear feedback on what students are capable of doing as writers. While students might be expected to be able to improve their written texts by way of acting on the lecturers' feedback, the system requires students to submit, not multiple drafts, but only one final draft of the essay. In this way, the formative role of teacher feedback (Glover and Brown, 2006) seems non-existent. The expectation of markers is that that single submission is as error-free as possible; and that over the years of their education, students have received sufficient feedback on earlier submissions to have learnt what constitutes correctness, and can therefore produce error-free texts.

In this paper, we hypothesize that in a largely product-focused writing context such as ours, students hold specific attitudes on self-editing that may detract from the quality of their writing, even though they might want to minimize errors that might occur in their work. This generated the research question: what are students' attitudes to self-editing?

\section{Why self-editing is important}

We regard self-editing as central to increasing students' facility in meeting their lecturers' expectations. Only the writer, via drafting and redrafting, reviewing (by self or peers), re-casting, and repeated self-editing, can respond to the entirety of textual detail, ranging from punctuation to word appropriateness to sentence length, cohesiveness, viewpoint, force of argument, pacing, and so on. We also regard self-editing as extremely important in the era of electronic communication because clicking "send" or "print" before attending to possible errors in form, content, and organization can be a source of embarassment for writers or annoyance for their readers. The promoting of self-editing practices therefore has lasting value for today's university student. More importantly, enhancing student self-editing capacity eliminates a culture of over-dependency on teachers, enabling the teacher to assume the role of a facilitator, co-learner or collaborator (Atkinson, 2003) during the writing process. It may also be important in reducing the teachers' workload, so that they can focus on providing feedback that is relevant to students' future work. It is also an important resource for learner-centred pedagogy (Vollmer, 2006) 
which places the student as an active agent in knowledge creation. Using our experience as teachers of a university writing course, we explore students' attitudes towards self-editing and identify possible reasons for these attitudes before making our recommendations.

\section{Theoretical framework}

When Krashen (1985) proposed his Monitor hypothesis to explain how L2 users apply their learnt knowledge of L2 rules to monitor (self-edit) their texts, he was of the view that self-editing was sometimes bad practice because of the resultant hesitant speech of L2 users. In contrast, however, we regard self-editing as a vital competency for L2 users in writing, especially, since the academic essay has become an entrenched assessment tool within higher education and must therefore be carefully crafted to optimise chances of success in assessment exercises.

Increasingly, studies in the field of L2 writing, especially research on revision and text quality, have come to view the writer as a responsible and active participant in the writing process. Focusing on what the student knows about communication and language, Yates and Kenkel (2002) adopt a learner interlanguage perspective on error correction, which they use to critique error correction procedures in the literature. They propose that "learners have principles which, if understood by the writing teacher, provide insights which are more useful than a target deviation perspective" (Yates and Kenkel, 2002: 31). Cresswell (2000) studied learner autonomy resulting from training in using the self-monitoring technique whereby students indicate their doubts by annotating their texts so that the lecturer can give feedback on these doubts and the essay itself. Results showed that learners appreciated the degree of independence gained and showed willingness to continue using the technique (Cresswell, 2000: 243). Similarly, Xiang (2004: 245) found self-monitoring particularly beneficial for high-achievers, although this applied only to the organizational aspect of their compositions. Both these findings show that students are not passive recipients of feedback but can be active participants in the construction and meaning of that feedback (Xiang 2004: 244). Charles (1990: 292) also proposed the self-monitoring technique and claimed that the technique "encourages students to look critically and analytically at their writing and to place themselves in the position of the readers".

The above studies questioned the effectiveness of established ways of giving feedback i.e. from the teacher to the student. Research in this area of L2 writing (Storch 2005, Brender 2002, Sugita 2006, Truscott 1999, Ferris 1996, Carson and Nelson 1996) is on whether and how teachers should correct errors in 
students' writing, whether teacher feedback improves students' writing proficiency, or whether peer-editing helps. Currently, debate rages around the question whether or not teacher's error feedback makes a difference. Over the past ten years the debate has featured Truscott against Ferris. The former argues that error feedback in L2 writing is counter-productive as it detrimentally affects learners' writing development and that it has not improved students' writing (Truscott 1999); while the latter argues that error feedback can improve language accuracy over a period of time (Ferris 1996). Williams (2003) suggested using individual conferencing as one way to explain the teacher's feedback to each student but this strategy is less feasible in large-class settings, such as ours. The literature reviewed by Glover and Brown (2006) claimed that in large classes the frequency and quantity of teacher feedback is reduced; consequently, the formative value of such feedback was lacking; and students argued that because written assignments were topic-focused, feedback lacked relevance to future assignments. Under these difficulties surrounding the effectiveness of feedback, additional techniques such as self-editing are needed.

Students' self-editing attitudes have, however, received relatively little attention in L2 research. Polio, Fleck, and Leder (1998) studied ESL students' editing for sentence level errors and Francis (2002) investigated the editing and correction strategies of much younger bilingual children. In both studies learners showed remarkable attentiveness with regard to their texts. Additionally, there are several writing manuals available that mention self-editing and the Internet offers access to numerous checklists for self-editing purposes. However, we still do not know clearly why errors that would seem to be author-correctable continue to end up in students' texts. The purpose of this paper therefore is to ascertain students' attitudes that may influence their ability to self-edit their written texts. Once identified, these attitudes may provide insights for instructional purposes for teachers of academic writing.

\section{The subjects}

Two out of the five classes taking an optional post-Year One course called 'Advanced Writing Skills' responded to a questionnaire and took part in the class discussion thereafter. (Both these activities were intended as consciousness-raisers for a self-editing activity that followed but is not reported here). The course is housed in a 'study skills' unit for student academic support programmes at our university, and is underpinned by behavioral psychological approaches characterized by genre writing drills. 
Altogether there were seventy students ( 23 males and 47 females) from seven different faculties as follows: the Faculty of Social Sciences (36), Humanities (12), Education (8), Science (7), Health Sciences (4), Business (2), and Engineering (1). These figures show the uneven popularity of the Advanced Writing Skills course across Faculties and disciplines, which can be attributed to the relative importance that the Faculties of Social Sciences, Humanities, and Education attach to essay writing, as reported by the students. The sample included forty-two second-year students, twenty-three third-years, and five fourth-years. Respondents' ages varied widely: fifty-two respondents were below twenty-five indicating that they left senior secondary school less than five years ago, which indicates that their familiarity with academic writing was more recent than the few who were over thirty. They were also a very complex multilingual group whose home languages included: Setswana (37 respondents), Kalanga (3), Sebirwa (3), Hindi (1), Ndebele (1), Setswapong (1) and Herero (1). Some spoke a combination of two or more home languages, either English and Setswana (14); or Kalanga and Setswana (6); or English and Sekgalagadi (2); or Setswana, Afrikaans and Herero (1). Despite this home language diversity, the sample shared similar school experiences of using English as the medium of instruction.

\section{Methodology}

Using, first, a questionnaire and then a class discussion, the study explored university students' self-editing attitudes in order to see whether students thought that self-editing improves textual quality. The three-item open-ended questionnaire, initially piloted with a different group of students taking the Advanced Writing Skills course, introduced students to the idea that writers must remain consciously in control of the writing and editing process (Cresswell, 2000:237) so as to minimize the errors that slip into the final draft. Again, taking hints from Cresswell (2000), the class discussion was based on students' memories of writing experiences.

\section{Findings}

The first item on the questionnaire was: "Do you think writers are able to selfedit their work themselves?" It sought respondents' perception of writers as autonomous individuals and as members of a writing community capable of self-editing and acting on the textual errors they spotted. All their responses communicated the attitude that self-editing is difficult, ineffective and complex. In the class discussion, they also expressed the view that they had not attained the status of 'writer', so as to be able to overcome these difficulties. (Indeed many self-editing online manuals convey a similar view.) Three such 
responses expressed the confounding nature of self-editing as follows: "yes, writers are able to self-edit their work but it is quite difficult because we tend to believe that we did everything correctly, thus defending our work"; and "because it is your work, you will understand it your own way, and some mistakes you will not identify"; and "they [writers] can [self-edit] and maybe not, because sometimes when you think you are reading what is written, in fact you are saying what you thought you were writing".

We further sought to know respondents' thoughts regarding the importance of self-editing by asking the question: "What in your opinion is the importance of self-editing to the text writer?" Respondents agreed that self-editing was an important part of writing because: "you [the writer] are the one who knows what you want to say and it will be difficult for another person who does not know what you want to say to do that for you"; "work with lots of mistakes turns off readers"; "I have realized how much I make mistakes when writing after I had my exercise marked"; "bumping into someone's editing mistakes is irritating". One respondent lamented the omission of self-editing activities in early education: "it is a bit difficult for most to grasp this concept [self-editing] because from elementary school we were taught in such a way that the teacher has to be the identifier of mistakes instead of us communicating through our writing". Another suggested that "time should be made for self-editing in exams and tests like probably after the test duration has lapsed"; while yet another suggested "maybe we can write our academic papers via a computer as it easily picks up errors".

We sought to see if students ever thought of alternative assistance with their drafts in the form of peer editing, by asking the question: "Do you ever ask a friend to edit your work before you submit it?". Almost half (34 out of 70) the respondents said they did. While they saw the value in peer editing, many saw it as merely a way to: "see if I have any mistakes"; "find each and every mistake'; "see mistakes I overlooked"; "be corrected by somebody"; "identify errors you the writer cannot see"; and "correct construction of words and spelling". One respondent wanted to "ensure that the work is readable".

Evidently, peer-editors mainly focus on the mechanics, and not on content and organization of ideas. However, this help was not sought by many because, as several respondents put it, "there was no time to show your work to a friend". The thirty-six respondents who said "no" to peer-editing gave reasons that indicated that they doubted if their peers were any better skilled than they were themselves. Peer-editing was also viewed with suspicion reflecting the competitiveness students attach to texts submitted for assessment and for that reason they were worried that peer-editing might result in "plagiarizing my points"; or "copying from me to improve [their] work and get higher marks"; 
or even "friends making fun of your mistakes"; or worse still "missing submission deadlines".

As expected, students' attitudes to self-editing are divided. On their ability to self-edit, they are unanimous that self-editing is complex, but that despite its complexity, it is important for the writer. However, on the value of asking a friend to assist in the editing, some students say that friends are helpful while others view that help with suspicion. The hypothesis of the study is therefore confirmed: that in a largely product-focused writing context such as ours, students' attitudes towards self-editing are not helping the quality of their writing, even though these students would want to take full responsibility to minimize the errors that occur in their work.

\section{Discussion of findings}

Increasingly, studies in the field of L2 writing, especially research on revision, have come to view the writer as a responsible and active participant in the writing process (Charles 1990, Cresswell 2000, Xiang 2004). However, as writers, students do not usually position themselves as co-researchers or as creators of new knowledge (McIntosh, 2001), a situation confirmed by their responses to the questionnaire. Responses also implied a strong need to minimize the sense of competition in the learning process. This is because developing academic writing skills in L2 can be theorized as a process of apprenticeship, where learning is viewed as a process of social participation rather than simply as acquisition of knowledge. The teacher's role, too, differs from that of a disseminator of knowledge. Within such a learning approach to knowledge acquisition, teacher and/or peer feedback may be viewed as part of the process of apprenticing students into legitimate participation. When student writers position themselves as communicators in a discourse community (consisting of their peers, their lecturer, and themselves), they become their own first readers of the texts they produce. However, evidence from the questionnaire and class discussion showed that mainly because writing tasks are competitively understood by students, audience is perceived as either assessors (their lecturer) or plagiarizers (their peers).

In the class discussion, students argued that feedback from their faculty lecturers was emphatic around correct use of the conventions of linguistic and textual features. This reinforces students' view of self-editing as a complex process shrouded in uncertainties. Students also rightly perceive a model of correctness to exist somewhere; a view advanced by the genre approach to academic literacy. Unfortunately, that ideal model seemed to remain obscure to them, either because their faculty lecturers do not model the genres for 
them, or the models are not made accessible to students; and also because such ideal models (or "genres") fail to produce autonomous writers because of an over-emphasis on the technical features of genres, rather than on their expressive resources. Additionally, the writing tasks are for purpose of compiling Continuous Assessment scores, and less because students need to practice and develop their discipline-based writing facility. Thus, the function of academic writing in the different faculties is seen to be mainly that of an evaluative tool that determines pass or failure; a view perpetuated by the absence of a real audience beyond the lecturer who chose the topic(s) and by the requirement to submit, not multiple drafts, but only one final product of the essay (Wright, 2006:90). As a result, students' attitudes to their writing tended to imply a process over which they had little control.

With regard to involving peers in editing one's work, one respondent indicated a reluctance to be critiqued by a friend because "friends may not want to disappoint you". This comment may be attributed to the Tswana cultural philosophy of botho which means compassion and caring. In the students' view, friends are expected to show their "goodness" in assessing what a friend has written; thus one respondent argued that, out of modesty, friends may not do a thorough job of editing because "they don't want to disappoint you", in case they are seen as bad or unsupportive friends. Carson and Nelson (1996) reported similar results among Chinese learners which they attributed to the Asian collectivist culture, saying that more successful peer interactions come from students who share a common language and cultural expectations than from students in heterogeneous cultural groupings. The same study identified additional cultural factors that underlie a reluctance to involve peers. One of these factors is "mutual status inequality" which was exemplified in the current study by one respondent who felt much belittled by peer-editing saying, "Someone who is not my lecturer reading my work!!! I feel as though they judge me". The other factor is "trustworthiness of peers' language proficiency". For instance one respondent dismissed her peers' linguistic proficiency as "most of their [peers] English is not very good... almost useless to have them do it [peer-edit]". These comments indicate a reluctance to accept guidance that comes from elsewhere other than from the lecturer, a problem attributable to classroom culture and power, where the teacher is perceived as the only source of knowledge. Such teacher-fronted perceptions of learning to write are not very helpful in large classes. For instance, at our university, semesterization reduced contact time per week for the Advanced Writing course from three to two hours, and due to heavy marking loads, student's work is returned long after submission but without any direct contact with the student. Often students do not even collect the marked scripts. Those who do are only curious to see their score but make very little use of the feedback. 
Earlier studies on revision cited in Cresswell (2000:236) found that students tended to edit for grammar at the expense of other textual elements such as logic, relevance, and appropriateness of content. Similar results are evident in the respondents' comments, where editing is only associated with their overemphasis on local, surface-level components and ignorance of global structures of texts. In the class discussion there were suggestions that since the computer can edit their work for them, there was little need to worry about errors. However, this is only partly true. For instance, with regard to essay content, the computer cannot supply the description, argumentation, thesis statement, focus, or differentiate factual and experiential information. The writer must also deal with the logical organization of ideas and arguments, the effectiveness of the introduction and conclusion, and the sequencing of ideas in order of importance. Thus the computer can only be a supplement to detecting textual inaccuracies. More importantly, when the peer's primary concern is "to see if I have any mistakes" or "to find each and every mistake", the attitude conveyed is that the original purpose of academic writing is not a genuine concern to understand something. Instead it is an opportunity for the reader to judge the degree of adherence or divergence to the writing conventions; and for the writer to display awareness of such textual features and; and that the form rather than the message is at the centre of writing. This view was further confirmed in the class discussion: among the main areas of writing mentioned by students during the discussion as requiring improvement were those relating to mechanics (referencing, grammar, punctuation, and spelling) and organization (sequencing of ideas, cohesion and coherence).

During the class discussion the students also revealed that, based on the feedback they were getting on their assignments, their faculty lecturers perceived the Advanced Writing Skills course as essentially remedial and that taking the course would enable them to write better. Such a deficit view of the students who take the course has implications which might be apparent in their written scripts in the Advanced Writing Skills course. Vollmer (2002) argues that a deficit perspective "sees them [L2 writers] as developmentally weak and their texts as riddled with errors". For their part the students said they found writing in English easy although they admitted that they needed help. Linking these statements to their responses to the questionnaire items, it is possible to suggest that greater autonomy via self-editing skills could enhance students' textual control better. Because these respondents did not position themselves as purposeful communicators, they often failed in their attempt to communicate meaning to their readers, probably as a result of the doubts they hold about their capabilities to do so. Such doubts are the result of recurrent disappointments from earlier assessed work. According to Garcia-Sanchez and de Caso-Fuertes (2005:273) a long history of failure influences task perseverance, the level of effort, and the degree of success achieved among other things. 
On the basis of the attitudes to self-editing ascertained in this brief study, a strong case can be made regarding the teaching of writing conventions to L2 writers. From an L1 perspective, McIntosh (2001) regarded writing conventions as domesticating and limiting because they discourage subjectivity. However, the important question for L2 writing instruction is "what benefit do students get, as writers, from a genre approach to literacy"? The textual inaccuracies in mechanics, organization, and content show that the learning of academic writing conventions is still needed by L2 writers if their sense of being in control is to be realized. Omitting the teaching of writing conventions marginalizes students within academia and relegates them to the back row of academic literacy. We are convinced that self-editing, initiated by way of direct instruction, requires a good or growing command of the conventions of writing. Without conscious engagement with and exposure to the conventions, students are at risk of failing and of being ever-subject to their lecturers' corrections, rather than developing their own facility.

\section{Recommendations}

Ideally, a genre approach to writing suggests that students acquaint themselves with actual examples of a variety of textual types. In this way they get to recognize the different linguistic and textual features. When this is followed by learner training in self-editing, students' texts have a basis of correctness to follow. Learners also need to be alerted to the expectations of the target audience. Additional error-detection mechanisms such as peers, the lecturer, and the computer promote a sense of discourse community within which meaning contained in the written text is constructed. Because the computer provides impersonal feedback on the mechanics (spelling, punctuation, and grammar) of writing, it protects the L2 writer against embarrassment and feelings of humiliation over the errors committed. It also saves the writers some effort, enabling them to focus beyond grammar and spelling on more global textual concerns such as logic, cohesion, word appropriateness, and overall textual organization.

\section{Future research}

Analyses in this brief survey of student attitudes to self-editing did not factor in the full range of variables involved. For example, it would be interesting for writing instruction to determine how age, gender, home language, and course and level of university study of the respondent impact on the attitudes to self-editing. There is also a need to investigate the impact on self-editing of contextual realities, such as large class sizes which reinforce classroom organizational practices that result in product-focused (rather than process-focused) 
writing and assessment practices. Due to the large number of learners involved, heavy marking loads are a constant burden for the lecturer. Hence, the intervening teacher feedback on the drafts and revisions are often impossible to give. Under these conditions, students' actual self-editing practices need to be documented and developed. The documenting of actual practices serves as indicators of how students are exhibiting control of the text they produce.

\section{Conclusion}

Overall the study has shown that although L2 writers in the research sample see self-editing as complex, they value it in reducing textual inaccuracies. Although a larger study sample would have provided more generalizable results, the findings of this brief attitudinal study contribute to the debate over how effectiveness within L2 writing can be developed: that, despite students' attitude that self-editing is complex, self-editing is a vital skill for improving textual quality; and writing instruction that nurtures its development is beneficial for purposes of developing autonomous L2 writers.

\section{References}

Atkinson, D. 2003. L2 writing in the post-process era: Introduction. Journal of Second Language Writing 12(1): 3-15.

Brender, A.S. 2002. The effectiveness of teaching articles to ESL students in writing classes using consciousness-raising methods. Dissertation Abstracts International, 63(1): 59A.

Carson, J. G., and Nelson, G. L. 1996. Chinese students' perceptions of ESL peer response group interaction. Journal of Second Language Writing, 5(1): 1-19.

Charles, M. 1990. Responding to problems in written English using a student self-monitoring technique. ELT Journal 44(4): 286 - 293.

Cresswell, A. 2000. Self-monitoring in student writing: Developing learner responsibility. ELT Journal 54(3): 235 - 244.

Ferris, D.R. 1996. The case for grammar correction in L2 writing classes: A response to Truscott. Journal of Second Language Writing, 8: 1-10.

Francis, N. 2002. Literacy, second language learning and the development of metalinguistic awareness: a study of bilingual children's perceptions of focus on form. Linguistics and Education 13(3): 373 - 404.

Halasek, K. 1999. A pedagogy of possibility: Bakhtinian perspectives on composition studies. Southern Illinois University Press, Carbondale, Illinois.

Garcia-Sanchez, J.N and de Caso-Fuertes, A.N. 2005. Comparison of the effects on writing attitudes and writing self-efficacy of three different training programs in students with learning disabilities. International Journal of Educational Research 43(4-5): 272-289.

Glover, C. and Brown, E. 2006. Written feedback for students: too much, too detailed or too incomprehensible to be effective? Downloaded in November 2009 from http://www. bioscience.heacademy.ac.uk/journal/vol7/beej-7-3.pdf 
Gray, R. 2004. Grammar correction in ESL/EFL writing classes may not be effective. The Internet TESL Journal, 10(11). Downloaded in May 2005 from, http://iteslj.org/

Krashen, S.D. 1985. The Input Hypothesis: Issues and Implications. London: Longman.

McIntosh, S. 2001. A critical writing pedagogy: Who benefits? Queensland Journal of Educational Research, 17(2): 152-163.

Nelson, G. and Carson, J. 2006. "Cultural issues in peer response: Revisiting 'culture." In Feedback in Second Language Writing: Contexts and Issues, K. Hyland and F. Hyland (eds). New York: Cambridge University Press, 42-59.

Polio, C., Fleck, C. and Leder, N. 1998. "If I only had more time:” ESL learners' changes in linguistic accuracy on essay revisions. Journal of Second Language Writing, 7(1): 43 - 68.

Storch, N. 2005. Collaborative writing: Product, process, and students' reflections. Journal of Second Language Writing, 14(3): 153-173.

Sugita, Y. 2006. The impact of teachers' comment types on students' revision. ELT Journal, 60(1): $34-41$.

Truscott, J. 1999. The case for "the case for grammar correction in L2 writing classes": A response to Ferris. Journal of Second Language Writing, 8: 111-122.

Vollmer, G. 2006. Sociocultural perspectives on second language writing. ERIC/CLL News Bulletin 25(2): 1-2.

Williams, J.G. 2003. Providing feedback on ESL students' written assignments. The Internet TESL Journal Vol. IX (10) Downloaded in September 2009 from http://iteslj.org/ Techniques/Williams-Feedback.html

Wright, J. 2006. Reflections on process writing. Journal for Language Teaching 40(2): 88-109.

Xiang, W. 2004. Encouraging self-monitoring in writing by Chinese students. ELT Journal 58(3):238 - 246 .

Yates, R. and Kenkel, J. 2002. Responding to sentence-level errors in writing. Journal of Second Language Writing, 11, 29-47.

Youngju, H. 2004. The effects of teacher's feedback on international students' self- correction abilities. M.A. thesis, Bringham Young University.

\section{Acknowledgements}

We would like to acknowledge the students taking the Advanced Writing Skills course. It was their efforts to become effective writers that led to this article. 